regimens (simulating a clinical trial) for our patients. In a study evaluating metered dose inhaler compliance in COPD, use of an electronic medication monitor with feedback on the accuracy of medication use improved compliance. ${ }^{11}$ This type of methodology could be used to improve adherence in COPD outside a clinical trial. Clearly, further research is needed to better understand the factors driving the phenomenon of improved outcomes in adherers. While it is disappointing that neither treatment with active drug nor disease severity had an impact on adherence, study participation was better in the combination treatment arm of the TORCH study which suggests that symptomatic improvement may positively affect the likelihood of compliance of a patient with COPD in the more global sense. This would be good news for our patients as the current analysis also suggests that the association between adherence and mortality risk reduction with combination therapy was even greater when only those in the treatment arm were analysed.

Competing interests: None.

Provenance and peer review: Commissioned; not externally peer reviewed.

Thorax 2009;64:922-923. doi:10.1136/thx.2009.121806

\section{REFERENCES}

1. Vestbo J, Anderson JA, Calverley PMA, et al. Adherence to inhaled therapy, mortality and hospital admission in COPD. Thorax 2009;64:939-43.

2. Rabe KF, Hurd S, Anzueto A, et al. Global strategy for the diagnosis, management, and prevention of chronic obstructive pulmonary disease: GOLD executive summary. Am J Respir Crit Care Med 2007;176 532-55.

3. McDermott MM, Schmitt B, Wallner E. Impact of medication nonadherence on coronary heart disease outcomes. A critical review. Arch Intern Med 1997;157:1921-9.
4. Horwitz RI, Horwitz SM. Adherence to treatment and health outcomes. Arch Intern Med 1993;153:1863-8

5. Anon. Influence of adherence to treatment and response of cholesterol on mortality in the coronary drug project. N Engl J Med 1980;303:1038-41.

6. Rand CS, Nides M, Cowles MK, et al. Long-term metered-dose inhaler adherence in a clinical trial. The Lung Health Study Research Group. Am J Respir Crit Care Med 1995;152:580-8

7. Epstein LH, Cluss PA. A behavioral medicine perspective on adherence to long-term medical regimens. J Consult Clin Psychol 1982;50:950-71.

8. Shumaker S, Ockene JK, Riekert KA. The handbook of health behavior and change. 3rd ed. New York: Springer, 2008.

9. James PN, Anderson JB, Prior JG, et al. Patterns of drug taking in patients with chronic airflow obstruction. Postgrad Med J 1985;61:7-10

10. Corden ZM, Bosley CM, Rees PJ, et al. Home nebulized therapy for patients with COPD: patient compliance with treatment and its relation to quality of life. Chest 1997;112:1278-82.

11. Nides MA, Tashkin DP, Simmons MS, et al. Improving inhaler adherence in a clinical trial through the use of the nebulizer chronolog. Chest 1993;104:501-7.

\title{
Airways disease: just nosing around?
}

\section{Glenis K Scadding, Harsha H Kariyawasam}

The airway is a continuous structure extending from the nasal vestibule to the alveoli, with the same pseudostratified ciliated columnar epithelium along much of its length. While an arbitrary line at the level of the vocal cords divides the airway into upper and lower subdivisions-a concept introduced in medical school anatomy tutorials and continued in patient care-airways disease does not conform to such specific anatomical regions. Upper and lower airway disease often coexist, with upper airway involvement often preceding that of the lower airway and even determining severity of disease and quality of life. ${ }^{1}$ This recognition has led to the development of the terms "united airways" and "one airway, one disease".

The nose is an air conditioner-filtering, warming and humidifying over 10000 litres of air daily before it progresses to the lungs. The nasal passages and associated structures bear the brunt

Royal National Throat Nose \& Ear Hospital and Royal Free Hospital NHS Trust, London, UK

Correspondence to: Dr G K Scadding, Royal National Throat Nose \& Ear Hospital, Department of Allergy and Medical Rhinology, 330 Gray's Inn Road, London WC1X 8DA, UK; g.scadding@ucl.ac.uk of environmental contact, being the first site of allergen, microbial and particle deposition. As a consequence, the upper airway is the location of a highly-developed innate and adaptive immune system. Effective mucociliary clearance is vital for respiratory health, as evidenced by the effects of defects such as primary ciliary dyskinesia (PCD) and cystic fibrosis. Sinus disease is almost universal in these patients, and even the subgroup of idiopathic bronchiectasis demonstrates high rates of chronic sinus infection, polyps and inflammation. ${ }^{2}$ Simple measures such as nasal douching can help with symptoms and quality of life. Measurement of nasal nitric oxide is simple and quick, ${ }^{3}$ and very low levels can alert the physician to the possibility of PCD before major lung damage is sustained, thus allowing the benefit of early physiotherapy.

An important lymphoid tissue mass (tonsils and adenoids) collectively termed Waldeyer's ring and prominent in childhood is a unique immunological organ surrounding the upper airway. It supports development and maturation of the immune system. A defective or compromised immune response often manifests initially with recurrent upper airway infection before involving the lungs or other organs. The upper airway epithelium can rapidly generate an array of immunomodulatory cytokines, chemokines and growth factors in response to injury, allergen or pathogen contact that can activate and sustain an airway inflammatory response. The submucosal tissue is rich in antigen presenting cells that can sample the environment, process material and subsequently navigate an immune response via induction of $\mathrm{T}$ cell function and immunoglobulin production. An over-excessive or dysregulated immune response can lead to allergic disease, predominantly Th2-mediated and possibly predisposed to by the presence of thymic stromal lymphopoietin in nasal epithelium. ${ }^{45}$ Alternatively, Th1 mechanisms give rise to serious systemic disorders such as Wegener's granulomatosis in which, again, upper airway manifestations usually appear first. ${ }^{6}$ Early diagnosis and rapid treatment can prevent further organ involvement such as renal disease and improve prognosis. The upper airway is also a site of manifestation of rheumatological disease such as Sjogren's syndrome or disorders of vascular remodelling impairment such as hereditary haemorrhagic telangiectasia. It is therefore evident that a broad spectrum of disease can present at the nasal level before involving the remainder of the airways, allowing a window of opportunity for diagnosis and early intervention.

Rhinitis means inflammation of the nasal lining, but the term is used to define a constellation of symptoms-nasal obstruction or congestion, rhinorrhoea 
(anterior and/or posterior), sneezing and nasal itch. Rhinitis, whether allergic or non-allergic, predisposes to asthma with an odds ratio of $3 .^{7}$ Certain forms of rhinitis exhibit even higher risks of developing asthma-for example, occupational rhinitis in wood workers, farmers ${ }^{8}$ and those allergic to house dust mite. Early diagnosis with either removal from allergen exposure or immunotherapy could prevent asthma, as has been shown for children allergic to grass pollen. ${ }^{9}{ }^{10}$ Most subjects with asthma have rhinitis, and even in those without nasal symptoms, upper airways inflammation is demonstrable. ${ }^{11}$ The reverse is also true-findings now explicable by the elegant studies of Wytske Fokkens and her colleagues who challenged the nose with allergen and showed eosinophil ingress to both nose and bronchi and vice versa. ${ }^{12} 13$

Seasonal allergic rhinitis is associated with increased airway hyperresponsiveness (AHR) ${ }^{14}$ which is treatable by reducing nasal inflammation. ${ }^{15}$ In fact, the same dose of corticosteroid is more effective in reducing AHR when applied nasally than when inhaled. ${ }^{16}{ }^{17}$ This may account for the discrepancy between lower airways inflammation and bronchial hyperreactivity which is becoming apparent from recent human trials of anti-interleukin (IL)-5 in which reduction of blood and sputum eosinophils failed to affect forced expiratory volume in $1 \mathrm{~s}$ while reducing exacerbations.

Most asthma exacerbations begin in the upper airway, often with a viral cold. ${ }^{18}$ Synergy exists between viral and allergic inflammation such that there is a nearly 20-fold risk of hospitalisation for asthma in the allergic child exposed to both relevant allergen plus rhinovirus. ${ }^{19}$ Our work on rhinitis co-morbidities such as otitis media with effusion suggests that, by reducing nasal inflammation in allergic children by regular intranasal corticosteroids, the effects of intermittent colds can be ameliorated. ${ }^{20} 21$ This approach needs to be extended to asthma both in adults and children with large well-designed prospective studies and also to chronic obstructive pulmonary disease (COPD). Large-scale retrospective series do show benefits to asthma by treatment of associated rhinitis, including reduced emergency visits, hospitalisation or both, ${ }^{22-24}$ although one would not appreciate this from reading the present national asthma guidelines. ${ }^{25}$

Severe or difficult asthma remains a clinical challenge with significant utilisation of health resources. In several recent studies, poor asthma control is associated with rhinitis. ${ }^{26} 27$ In a UK general practice study of 4429 patients with asthma, bothersome rhinitis gave an odds ratio of $>4$ for poor asthma control (as defined by an Asthma Control Questionnaire of $>1.25$ ), similar to that for smoking. Mild rhinitis was more likely to worsen asthma (odds ratio 1.97) than poor adherence to treatment (odds ratio 1.29). ${ }^{28}$ Yet in asthma clinics it is routine to ask about smoking and adherence but to ignore rhinitis.

Chronic rhinosinusitis is a concept possibly less familiar than rhinitis to chest physicians. It implies inflammation of the nose and of the sinus linings and can include nasal polyposis. ${ }^{29}{ }^{30}$ It is consistently associated with increasing severity of asthma. ${ }^{31} 32$ Asthmatic patients with nasal polyposis and aspirin intolerance have the highest rates of exacerbation and hospital admissions. ${ }^{33}$ Again this disorder begins in the upper airway-often in young adults with symptoms of a severe cold which fails to resolve. Nasal polyps, asthma and aspirin sensitivity develop over the following few years. ${ }^{34}$ The upper airway, because of its accessibility, has proved invaluable in investigating the pathophysiology of this disease, in diagnosing it safely by nasal aspirin challenge $e^{35}$ and as a route of treatment using topical aspirin desensitisation. ${ }^{36}$

Staphylococcus aureus is present in nasal polyps and $S$ aureus enterotoxin B further shifts the local cytokine pattern toward Th2 cytokines but disfavours the $\mathrm{T}$ regulatory cytokines IL-10 and transforming growth factor- $\beta_{1}$. Furthermore, $S$ aureus-derived enterotoxins influence local immunoglobulin synthesis and induce polyclonal immunoglobulin E production which may contribute to severe inflammation via activation of mast cells. ${ }^{37}$ This observation has been extended to the bronchial mucosa ${ }^{38}$ and may be relevant to intrinsic asthma. ${ }^{39}$

Studies in animal models have shown that localised allergen provocation is associated with a systemic inflammatory response with bone marrow increases in inflammatory cell progenitors. ${ }^{40}$ The demonstration that antigen stimulation of any part of the respiratory mucosa leads to a ripple effect along the entire airway $^{12} 13$ must suggest that other mechanisms of nasal mucosal activation and damage-for example, infection or particulate stress such as tobacco smokehave the potential to exacerbate lower airway disease. While studies in COPD are currently limited, the nasal airway in patients with stable COPD has increased inflammation ${ }^{41}{ }^{42}$ and a rapid response to local histamine provocation with neutrophil activation and mucin secretion. ${ }^{43}$ The suggestion is that an immunologicallyprimed upper airway is present in COPD and can recognise and initiate a rapid local immune response to microbial and particulate activation which contributes to the increase in bronchial inflammation found at exacerbation. Further studies are needed to evaluate such mechanisms, as there may be important implications for intervention in COPD exacerbations at the nasal level.

In this issue of Thorax a series of focused reviews is initiated which evaluate the current evidence that supports an important role for the upper airway in the initiation, maintenance and exacerbation of respiratory diseases (see page 999). The importance of assessing the upper airway in a respiratory clinic is highlighted. It is obvious that much work is still needed to broaden our understanding of the mechanistic interactions of airway disease and how intervention at the level of the upper airway will impact on overall disease response and quality of life. Given that the nasal mucosa is an easily accessible site for tissue sampling and delivery of interventions, development of nasal models of disease must be considered. Prospective studies to evaluate the benefits of nasal intervention in specific disease settings are a priority; any trial of treatment for asthma should automatically include assessment of upper airway changes and vice versa. The American Thoracic Society and the European Respiratory Society have recently released official standards regarding asthma evaluation for clinical trials and practice which are disappointingly parochial. Future asthma guidelines should incorporate guidance on the evaluation of upper airway manifestations of disease and intervention strategies. Asthma control needs replacing with airways control. A multidisciplinary approach with respiratory physicians working with ENT surgeons with training in rhinology is ideal, but probably unlikely in light of present financially-driven health care. The future respiratory physician should therefore be trained in upper as well as lower airways medicine since, by assessing the whole airway, it is anticipated that better disease understanding, control, improved quality of life and possibly prevention will be achieved with ultimate benefits for patients.

Competing interests: None.

Provenance and peer review: Commissioned; not externally peer reviewed.

Thorax 2009;64:923-925. doi:10.1136/thx.2009.125047 


\section{REFERENCES}

1. Bousquet J, Khaltaev N, Cruz AA, et al. Allergic Rhinitis and its Impact on Asthma (ARIA) 2008 update (in collaboration with the World Health Organization, GA(2)LEN and AllerGen). Allergy 2008;63(Suppl 86):8-160.

2. Guilemany JMM, Angrill J, Alobid I, et al. United airways again: high prevalence of rhinosinusitis and nasal polyps in bronchiectasis. Allergy 2009:64:790-7.

3. Scadding G. Nitric oxide in the airways. Curr Opin Otolaryngol Head Neck Surg 2007;15:258-63.

4. Zhou B, Comeau MR, De Smedt T, et al. Thymic stromal lymphopoietin as a key initiator of allergic airway inflammation in mice. Nat Immunol 2005:6:1047-53

5. Mou Z, Xia J, Tan Y, et al. Overexpression of thymic stromal lymphopoietin in allergic rhinitis. Acta Otolaryngol 2009;129:297-301.

6. D'Cruz DP, Baguley E, Asherson RA, et al. Ear, nose, and throat symptoms in subacute Wegener's granulomatosis. BMJ 1989;299:419-22.

7. Guerra S, Sherrill DL, Martinez FD, et al. Rhinitis as an independent risk factor for adult-onset asthma. J Allergy Clin Immunol 2002;109:419-25.

8. Karjalainen A, Martikainen R, Klaukka T, et al. Risk of asthma among Finnish patients with occupational rhinitis. Chest 2003:123:283-8.

9. Moller C, Dreborg S, Ferdousi HA, et al. Pollen immunotherapy reduces the development of asthma in children with seasonal rhinoconjunctivitis (the PATstudy). J Allergy Clin Immunol 2002;109:251-6.

10. Jacobsen L, Niggemann B, Dreborg S, et al. Specific immunotherapy has long-term preventive effect of seasonal and perennial asthma: 10-year follow-up on the PAT study. Allergy 2007:62:943-8.

11. Gaga M, Lambrou P, Papageorgiou N, et al. Eosinophils are a feature of upper and lower airway pathology in non-atopic asthma, irrespective of the presence of rhinitis. Clin Exp Allergy 2000;30:663-9.

12. Braunstahl GJ, KleinJan A, Overbeek SE, et al. Segmental bronchial provocation induces nasal inflammation in allergic rhinitis patients. Am J Respir Crit Care Med 2000:161:2051-7.

13. Braunstahl GJ, Overbeek SE, KleinJan A, et al. Nasal allergen provocation induces adhesion molecule expression and tissue eosinophilia in upper and lower airways. J Allergy Clin Immunol 2001;107:469-76.

14. Madonini E, Briatico-Vangosa G, Pappacoda A, et al Seasonal increase of bronchial reactivity in allergic rhinitis. J Allergy Clin Immunol 1987;79:358-63.

15. Corren J, Adinoff AD, Buchmeier $A D$, et al. Nasal beclomethasone prevents the seasonal increase in bronchial responsiveness in patients with allergic rhinitis and asthma. J Allergy Clin Immunol 1992;90:250-6.
16. Aubier M, Levy J, Clerici $\mathbf{C}$, et al. Different effects of nasal and bronchial glucocorticosteroid administration on bronchial hyperresponsiveness in patients with allergic rhinitis. Am Rev Respir Dis 1992;146:122-6.

17. Stelmach R, do Patrocinio TN, Ribeiro M, et al. Effect of treating allergic rhinitis with corticosteroids in patients with mild-to-moderate persistent asthma. Chest 2005;128:3140-7.

18. Papadopoulos NG, Xepapadaki P, Mallia P, et al. Mechanisms of virus-induced asthma exacerbations: state-of-the-art. A GA2LEN and InterAirways document. Allergy 2007:62:457-70.

19. Murray CS, Poletti G, Kebadze T, et al. Study of modifiable risk factors for asthma exacerbations: virus infection and allergen exposure increase the risk of asthma hospital admissions in children. Thorax 2006;61:376-82.

20. Alles R, Parikh A, Hawk L, et al. The prevalence of atopic disorders in children with chronic otitis media with effusion. Pediatr Allergy Immunol 2001:12:102-6.

21. Parikh A, Alles R, Hawk L, et al. Treatment of allergic rhinitis and its impact in children with chronic otitis media with effusion. J Audiol Med 2000;9:104-17

22. Adams RJ, Fuhlbrigge AL, Finkelstein JA, et al. Intranasal steroids and the risk of emergency department visits for asthma. J Allergy Clin Immunol 2002; 109:636-42.

23. Crystal-Peters J, Neslusan C, Crown WH, et al. Treating allergic rhinitis in patients with comorbid asthma: the risk of asthma-related hospitalizations and emergency department visits. J Allergy Clin Immunol 2002;109:57-62.

24. Corren J, Manning BE, Thompson SF, et al. Rhinitis therapy and the prevention of hospital care for asthma: a case-control study. J Allergy Clin Immunol 2004;113:415-9.

25. British Thoracic Society. British guideline on the management of asthma. Thorax 2008;63(Suppl 4):iv1-121.

26. Ponte EV, Franco R, Nascimento HF, et al. Lack of control of severe asthma is associated with coexistence of moderate-to-severe rhinitis. Allergy 2008;63:564-9.

27. Magnan A, Meunier JP, Saugnac C, et al. Frequency and impact of allergic rhinitis in asthma patients in everyday general medical practice: a French observational cross-sectional study. Allergy 2008;63:292-8.

28. Clatworthy J, Price D, Ryan D, et al. The value of self-report assessment of adherence, rhinitis and smoking in relation to asthma control. Prim Care Respir J 2009 Jun 26. doi: 10/4104/pcrj.2009.00037 [Epub ahead of print].
29. Fokkens W, Lund V, Bachert C, et al. EAACI position paper on rhinosinusitis and nasal polyps executive summary. Allergy 2005;60:583-601.

30. Thomas M, Yawn BP, Price D, et al. EPOS primary care guidelines: European Position Paper on the primary care diagnosis and management of rhinosinusitis and nasal polyps 2. Prim Care Respir J 2008;17:79-89

31. Bresciani M, Paradis L, Des RA, et al. Rhinosinusitis in severe asthma. J Allergy Clin Immunol 2001;107:73-80.

32. ten Brinke A, Grootendorst DC, Schmidt JT, et al. Chronic sinusitis in severe asthma is related to sputum eosinophilia. J Allergy Clin Immunol 2002:109:621-6.

33. Ceylan E, Gencer M, San I. Nasal polyps and the severity of asthma. Respirology 2007;12:272-6.

34. Szczeklik A, Nizankowska E, Duplaga M. Natural history of aspirin-induced asthma. AIANE Investigators. European Network on Aspirin-Induced Asthma. Eur Respir J 2000;16:432-6.

35. Nizankowska-Mogilnicka E, Bochenek G, Mastalerz L, et al. EAACI/GA2LEN guideline: aspirin provocation tests for diagnosis of aspirin hypersensitivity. Allergy 2007;62:1111-8.

36. Ogata N, Darby Y, Scadding G. Intranasal lysineaspirin administration decreases polyp volume in patients with aspirin-intolerant asthma. J Laryngol Otol 2007;121:1156-60.

37. Bachert C, Zhang N, Patou J, et al. Role of staphylococcal superantigens in upper airway disease. Curr Opin Allergy Clin Immunol 2008;8:34-8.

38. Bachert C, Gevaert P, Howarth P, et al. IgE to Staphylococcus aureus enterotoxins in serum is related to severity of asthma. J Allergy Clin Immunol 2003;111:1131-2

39. Barnes PJ. Intrinsic asthma: not so different from allergic asthma but driven by superantigens? Clin Exp Allergy 2009;39:1145-51.

40. Saito H, Howie K, Wattie J, et al. Allergen-induced murine upper airway inflammation: local and systemic changes in murine experimental allergic rhinitis. Immunology 2001;104:226-34.

41. Hurst JR, Wilkinson TM, Perera WR, et al Relationships among bacteria, upper airway, lower airway, and systemic inflammation in COPD. Chest 2005; 127:1219-26.

42. Hens G, Vanaudenaerde BM, Bullens DM, et al. Sinonasal pathology in nonallergic asthma and COPD: 'united airway disease' beyond the scope of allergy. Allergy 2008;63:261-7.

43. Nihlen U, Andersson M, Lofdahl CG, et al. Nasal neutrophil activity and mucinous secretory responsiveness in COPD. Clin Physiol Funct Imaging 2003;23:138-42. 